
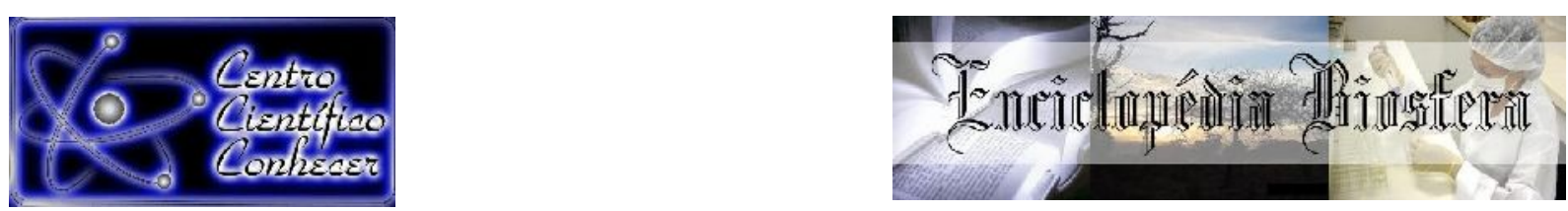

\title{
INTERFACES ENTRE PESQUISA E ENSINO: ESTRATÉGIAS PARA SENSIBILIZAÇÃO DOS ALUNOS DO ENSINO BÁSICO PARA CONSERVAÇÃO DA FAUNA SILVESTRE, EM ESPECIAL O TAYASSU PECARI
}

Renan Luiz Albuquerque Vieira ${ }^{1^{*}}$, Hanilton Ribeiro de Souza ${ }^{2}$, Heitor José Bento ${ }^{3}$, Thaise da Silva Oliveira Costa ${ }^{4}$, Marcus Antônio Rossi Feliciano ${ }^{1}$

${ }^{1}$ Programa de Pós-Graduação em Ciência Animal nos Trópicos, Universidade Federal da Bahia, campus Ondina, Avenida Adhemar de Barros, № 500, Salvador, Bahia, Brasil -

(renan.albuquerque@hotmail.com).

${ }^{2}$ Docente, Universidade do Estado da Bahia, campus V, Loteamento Jardim Bahia, $s / n^{\circ}$, Santo Antônio de Jesus, Bahia, Brasil.

${ }^{3}$ Programa de Pós-graduação em Ciências Veterinárias, Faculdade de Medicina Veterinária, Universidade Federal de Mato Grosso, Av. Fernando Correa da Costa, ํㅜ 2.367, bairro Boa Esperança, Cuiabá, Mato Grosso, Brasil.

${ }^{4}$ Docente, Faculdade de Ciências Sociais Aplicadas, BR 101, Km 808, $n^{\circ} 1130$, Itamaraju, Bahia, Brasil.

Recebido em: 15/02/2021 - Aprovado em: 15/03/2021 - Publicado em: 30/03/2021 DOI: 10.18677/EnciBio_2021A9

\begin{abstract}
RESUMO
Dentre as diversas alternativas empregadas na tentativa de solucionar os problemas ambientais, a educação ambiental torna-se uma importante ferramenta de ensino e sensibilização para construir uma nova ética ambiental. Nesta perspectiva, como parte da pesquisa de doutorado, realizada com alunos da $3^{\text {a }}$ série do ensino médio, do Colégio Estadual do Campo de Castro Alves, na cidade de Castro Alves, Bahia, objetivou-se analisar a concepção destes acerca da conservação dos animais silvestres, especialmente do Tayassu pecari, sensibilizando-os quanto à influência das atitudes humanas sobre as relações ecológicas. Foi realizada uma entrevista estruturada por meio da aplicação de questionários, contendo 13 questões, subjetivas e de múltipla escolha, para que se pudesse avaliar a concepção prévia dos alunos. Após a análise dos dados, foi ministrada uma palestra sobre educação ambiental, destacando estratégias para a conservação do queixada, bem como a explicação de dados obtidos no experimento de doutorado, inter-relacionando pesquisa e ensino. Verificou-se que, antes das atividades efetuadas na sala de aula, relativas à educação ambiental, os estudantes detinham um conhecimento básico sobre legislação ambiental e sobre as diferenças entre animais domésticos, silvestres e selvagens. E também não conheciam os queixadas. No entanto, apresentaram relativa preocupação com o bem estar animal e o cumprimento das leis ambientais, condições fundamentais para construção de uma nova consciência ecológica. A educação ambiental, bem como as inter-relações entre pesquisa e ensino, mostraram-se eficazes para informar e conscientizar sobre questões relacionadas à conservação do meio ambiente, sendo, portanto, um instrumento essencial na mitigação dos problemas ambientais.
\end{abstract}

PALAVRAS-CHAVE: Animais silvestres, conservação, ensino-pesquisa. Queixadas. ENCICLOPÉDIA BIOSFERA, Centro Científico Conhecer - Jandaia-GO, v.18 n.35; p. 113 


\title{
INTERFACES BETWEEN RESEARCH AND EDUCATION: STRATEGIES FOR AWARENESS OF BASIC EDUCATION STUDENTS FOR THE CONSERVATION OF THE WILD FAUNA, ESPECIALLY TAYASSU PECARI
}

\begin{abstract}
Among the various alternatives used in an attempt to solve environmental problems, environmental education becomes an important teaching and awareness tool to build a new environmental ethics. In this perspective, as part of the doctoral, research carried out with students of the 3 series grade of high school, from the Colégio Estadual do Campo de Castro Alves, in the city of Castro Alves, Bahia, the objective was to analyze their conception about the conservation of wild animals, especially of Tayassu pecari, making them aware of the influence of human attitudes on ecological relations. A structured interview was carried out through the application of questionnaires, containing 13 questions, subjective and multiple choice, so that the previous conception of the students could be evaluated. After analyzing the data, a lecture on environmental education was given, highlighting strategies for the conservation of the peccaries, as well as the explanation of data obtained in the doctoral experiment, interrelating research and teaching. It was found that, before the activities carried out in the classroom, related to environmental education, the students had a basic knowledge about environmental legislation and about the differences between domestic, wild and wild animals. Nor did they know the peccaries. However, they were relatively concerned with animal welfare and compliance with environmental laws, fundamental conditions for building a new ecological awareness. Environmental education, as well as the interrelationships between research and teaching, proved to be effective in informing and raising awareness about issues related to environmental conservation, being, therefore, an essential tool in the mitigation of environmental problems.
\end{abstract}

KEYWORDS: Conservation, teaching-research, white-lipped peccaries, wildlife

\section{INTRODUÇÃO}

A fauna silvestre apresenta-se como de fundamental importância para a manutenção e preservação da biodiversidade, atuando como polinizadores e dispersores de sementes, além de realizar o controle das populações de presas dentro da sua cadeia alimentar (VIEIRA et al., 2019). Dentre os fatores que promovem o declínio nas populações de animais silvestres, a caça merece destaque, tendo em vista que sua prática tem levado à extinção de diversas espécies nativas, afetando o equilíbrio dos ecossistemas naturais (DIAS et al., 2018). Em especial, o queixada (Tayassu Pecari), mamífero silvestre pertencente à família Tayassuidae, que encontrase em declínio ao longo da sua área de ocorrência devido à caça e destruição de seu hábitat (KEUROGHLIAN et al., 2013). Diante da importância da espécie para a manutenção dos ecossistemas, é preciso estabelecer práticas que reduzam seu declínio populacional e que levou à espécie a ser classificada como vulnerável pela União Internacional para Conservação da Natureza (IUCN) (KEUROGHLIAN et al., 2013).

A partir da compreensão de que os recursos ambientais são esgotáveis e estão sofrendo acelerado declínio, surge a necessidade do uso consciente/racional dos recursos naturais. Desta forma, a perspectiva da sustentabilidade tem se fortalecido e ENCICLOPÉDIA BIOSFERA, Centro Científico Conhecer - Jandaia-GO, v.18 n.35; p. 114 2021 
novos modelos de desenvolvimento têm sido propostos, com o objetivo de garantir a manutenção da qualidade ambiental para que assim, esta e as futuras gerações possam continuar a usufruir dos recursos naturais disponíveis. O uso sustentável dos recursos naturais tornou-se, então, uma necessidade e não uma escolha, sendo mais um processo do que um estado. Reconhecido como um tema atual, representa um grande desafio no Antropoceno (ALMEIDA et al., 2018; MOSSI, 2019; MUNIZ; PAZMINO, 2019).

A degradação ambiental surge no contexto do crescimento e da globalização da economia, fenômenos estes característicos da modernidade em função do domínio humano. As reflexões atuais vão além do entendimento da "degradação das bases de sustentabilidade ecológica em detrimento do processo econômico, mas se manifestam também como uma crise de civilização, que questiona a racionalidade do sistema social, os valores, os modos de produção e os conhecimentos que os sustentam" (LEFF, 2001), provocando o surgimento de um paradigma que exige uma nova ética ambiental do ser humano.

A ética ambiental surge com objetivo de combater a ideia do antropocentrismo, na tentativa de retirar o homem do centro do universo, a partir da conscientização de que a seguridade da vida humana depende diretamente da conservação das demais espécies (PELIZZOLI, 2002). O conceito de ética ambiental promove reflexões acerca dos valores relacionados à ética antropocêntrica, na qual o homem, por apresentar consciência de si próprio, se porta com superioridade em relação aos demais animais e, se colocando, portanto, no centro do universo. É nesse contexto que o interesse capitalista se fundamenta, trazendo grandes transtornos e perdas ao meio ambiente (PELIZZOLI, 2002).

Diversas alternativas têm sido empregadas na tentativa de solucionar problemas ambientais, dentre elas a educação ambiental apresenta-se como uma ferramenta mitigadora, apontada por vários autores como um dos caminhos para minimizar e ou solucionar os impactos ambientais (ROSÁRIO, 2019). Neste sentido, ensino e aprendizagem sobre as questões ambientais surge como possibilidade de promover transformações no atual quadro de degradação ambiental (MUNIZ; PAZMINO, 2019). Os princípios da educação ambiental baseiam-se na compreensão, conscientização e desenvolvimento de novos padrões de conduta para com o meio ambiente, por meio da utilização racional dos recursos naturais (MUNIZ; PAZMINO, 2019; ROSÁRIO, 2019).

Diversas fontes de comunicação que os estudantes frequentemente possuem contato, como televisão, jornais e internet, muitas vezes não estão relacionadas ao ensino formal, e parecem não fornecer informações adequadas sobre a biodiversidade, ao menos no que diz respeito a desenvolver nos estudantes uma percepção sensibilizada sobre a conservação das espécies (SAMPAIO, 2017). Neste sentido, as escolas são excelentes laboratórios para investigações temáticas como, por exemplo, a conservação da biodiversidade, sobretudo àquelas situadas em ambientes rurais. Os professores possuem um importante papel para a implantação da Educação Ambiental em suas aulas, potencializando o estabelecimento dessas práticas nas instituições de ensino (ALKIMIN et al., 2019; MUNIZ; PAZMINO, 2019).

No entanto, para que a Educação Ambiental seja inserida no ambiente escolar, é necessário que haja uma reformulação da formação dos professores, investindo no seu protagonismo ao abordar temas ambientais como atividades nucleares nas escolas (ALKIMIN et al., 2019). Desta forma, um senso crítico pode ser despertado nos ENCICLOPÉDIA BIOSFERA, Centro Científico Conhecer - Jandaia-GO, v.18 n.35; p. 115 2021 
estudantes, sensibilizando-os para as práticas de conservação, bem como, de que dependemos do meio ambiente para sobreviver (CARVALHO et al., 2020).

Desta forma, é de vital importância que sejam reforçadas as inter-relações entre pesquisa e ensino, a fim de desenvolver a consciência ambiental coletiva, mas sobretudo, a investigação científica no ensino básico, despertando nos alunos o interesse para a pesquisa e conservação da biodiversidade. Partindo deste princípio, objetivou-se por meio desta pesquisa de campo qualitativa, investigar e analisar a concepção dos alunos do Ensino Básico do Colégio Estadual do Campo de Castro Alves, acerca da conservação dos animais silvestres, em especial do $T$. pecari e, em contrapartida, conscientizá-los no que diz respeito às relações ecológicas, ressaltando a influência das atitudes humanas sobre estas relações, verificando a importância do estudo sobre a biodiversidade nas escolas.

\section{Lócus da Pesquisa}

\section{MATERIAL E MÉTODOS}

A pesquisa foi realizada no Colégio Estadual do Campo de Castro Alves, localizado na cidade Castro Alves, Bahia. Com Latitude: $12^{\circ} 44^{\prime} 51^{\prime \prime}$ Sul, e Longitude: 39॰ 25' 52" Oeste. O município conta com remanescentes florestais da Mata Atlântica, dentre estes a Serra da Jiboia, uma Área de Preservação Ambiental (APA), situada na porção sul do Recôncavo Baiano, que abriga uma rica biodiversidade de fauna e flora. Esta serra possui uma área total de aproximadamente 23.000 hectares ainda cobertos por remanescentes de Mata Atlântica, sendo que cerca de 7.000 hectares são considerados Mata Atlântica em estágio avançado de regeneração. Este fato reforça a importância da educação ambiental para a conscientização e a conservação dos recursos naturais.

\section{Coleta de Dados}

O público alvo desta pesquisa foram 42 discentes da $3^{a}$ série do ensino médio, do turno matutino, composta em sua maioria por alunos de áreas rurais, no período de 16 a 27 de setembro de 2019. Com o intuito de investigar o conhecimento destes alunos a respeito da diversidade e da conservação de fauna, especialmente dos queixadas, objeto do projeto desenvolvido pelos autores. Durante a primeira parte do estudo foi realizada uma entrevista estruturada por meio da aplicação de questionários, contendo 13 questões - subjetivas e de múltipla escolha -, para que os alunos tivessem liberdade para expressar seus conhecimentos acerca do tema biodiversidade, conservação de animais silvestres, definições zoológicas, atitudes frente aos animais, percepção ambiental e conhecimento sobre os queixadas. Os alunos que concordaram em responder o questionário tiveram sua identidade preservada, e com consentimento livre e esclarecido para desistir da pesquisa a qualquer momento.

As questões abordadas encontram-se distribuídas no quadro 1. 
QUADRO 1: Questionário aplicado com os alunos.

1. O que são animais silvestres?

2. Qual a diferença entre animal silvestre, doméstico e animal selvagem? Cite três exemplos (espécies) de cada.

3. Cite 3 espécies de animais da fauna brasileira ameaçadas de extinção.

4. Você costuma caçar animais silvestres? Por quê? Raramente ( ) Não. Quais?

5. Você possui animais em casa?
7. Sabe o que é necessário fazer para possuir um animal diferente dos tradicionais em casa? Gostaria de ter um? Qual?

8. Você já ouviu falar sobre tráfico de animais silvestres? $O$ que você entende sobre o assunto? Quais as consequências desse tipo de atividade?

9. Como podemos contribuir para a conservação da biodiversidade?

10. Já trabalhou 0 assunto conservação da biodiversidade em sala de aula? Em qual disciplina? Qual a importância desse tema na sua opinião?

11. Você conhece ou já ouviu falar nos queixadas? Sabe o que poderia ser feito para contribuir com a conservação desta espécie?

12. Você acha que a biotecnologia pode auxiliar na conservação das espécies? De que forma?
6. Qual sua atitude ao receber/encontrar um animal silvestre?

( ) Criar e cuidar ( ) Acionar o IBAMA ( ) Soltar o animal ( ) Matar ( ) Vender/consumir ( ) outro:

Fonte: Questionário. Elaborado pelos autores, (2019).

A opção de trabalhar com a $3^{a}$ série do Ensino Médio se deu em virtude desse nível de ensino ser considerado, no âmbito da atual Lei de Diretrizes e Bases da Educação Nacional e Parâmetros Curriculares Nacionais - PCN (BRASIL, 2000), a etapa final do ensino básico, possibilitando investigar conhecimentos sobre biodiversidade adquiridos nessa etapa de escolarização. Utilizou-se, como instrumento de pesquisa, a entrevista 'em profundidade', que teve como orientação básica um roteiro semiestruturado, contendo 13 questões principais. Além disso, optou-se também por colher e analisar relatos escritos dos alunos após a realização da palestra, na mesa de diálogos, quando expressaram suas opiniões, avaliando o trabalho realizado.

Trata-se de uma pesquisa de campo qualitativa na qual a aplicação de um questionário concedeu a possibilidade de um tratamento interpretativo e estatístico das informações (CRESWELL, 2007). Durante a análise das informações foi relevante 
interpretar qualitativamente as ideias apresentadas pelos estudantes às questões formuladas. Os dados foram avaliados de maneira geral "como um todo" e posteriormente analisados levando em considerações as seguintes variáveis: Correlação entre o perfil de respostas e o sexo. A frequência de respostas auxiliou na criação das categorias.

\section{Palestra e Mesa de Diálogo}

A segunda parte da pesquisa refere-se à produção de um metatexto que combina descrição com interpretação, organizado a partir das categorias construídas ao longo da análise. Após a análise dos dados, foi ministrada uma palestra sobre educação ambiental, destacando estratégias para a conservação do queixada, bem como a explicação de dados obtidos no experimento de doutorado, considerando a interface ensino e pesquisa na promoção do conhecimento. Por fim, foram esclarecidas as dúvidas presentes no questionário. Após a palestra, os alunos puderam assistir o documentário "Animais seres sencientes", para auxiliar na sedimentação do conteúdo discutido. Por fim, realizou-se uma mesa de discussão, para que os alunos pudessem explanar seus pontos de vista e relatar (oral e de forma escrita) se houve mudança em sua percepção a respeito da conservação dos animais silvestres, bem como quanto às técnicas e estratégias de conservação do queixada.

\section{Análise estatística}

Os dados obtidos foram analisados por meio de estatística descritiva, através do cálculo das frequências relativas das respostas fornecidas, com resultados apresentados em porcentagens. A análise dos dados qualitativos foi realizada por meio de análise de Discurso do Sujeito Coletivo-DSC, conforme descrito por Lefevre et al. (2000).

\section{RESULTADOS E DISCUSSÃO}

Quando questionados a respeito do que são animais silvestres, o perfil de resposta dos alunos foi de que se trata de animais que vivem na selva, animais criados na natureza ou soltos na natureza ou ainda animais que as pessoas consomem, citando como exemplo os tigres, leões, cobras, girafas, macacos e pássaros.

Quando indagados sobre a diferença entre animal silvestre, selvagem e doméstico, os alunos não souberam responder ao certo. No entanto, associaram os animais domésticos a animais dóceis e que estão acostumados com a presença dos serem humanos, citando como exemplo cães, gatos e galinhas, já para os animais silvestres e selvagens os estudantes os definiram como animais agressivos e que costumam atacar os humanos, sendo necessário, portanto, manter distância, a exemplo dos leões, tigres, onça e cobras peçonhentas. Nesta questão, os alunos apresentaram um conhecimento superficial acerca das diferenças que definem o animal como doméstico, silvestre e selvagem.

Segundo a Portaria/IBAMA no 93, de 07 de julho de 1998 (BRASIL, 1998), animais domésticos são todos aqueles que através de processos tradicionais e sistematizados de manejo e/ou melhoramento zootécnico tornaram-se domésticos, apresentando características biológicas e comportamentais em estreita dependência do homem. Já os animais silvestres são todos aqueles animais pertencentes às espécies nativas, migratórias e quaisquer outras, aquáticas ou terrestres que tenham seu ciclo de 
vida ocorrendo dentro dos limites do Território Brasileiro ou águas jurisdicionais brasileiras. Por fim, animais selvagens são todos aqueles pertencentes às espécies ou subespécies cuja distribuição geográfica não inclui o Território Brasileiro e as espécies ou subespécies introduzidas pelo homem, inclusive domésticas em estado asselvajado.

$\mathrm{Na}$ terceira questão, ao pedir que fossem citadas três espécies de animais da fauna brasileira ameaçadas de extinção, os estudantes citaram: arara azul, mico leão dourado, lobo guará, hiena, zebra, elefante, onça pintada, jaguatirica, tigre, tamanduá, macaco aranha, tucano, abelha, boto-cor-de-rosa, leão, leopardo, arara vermelha, tatu, teiú, saguim, tatu bola, tatu canastra, preguiça, papagaio, veado e capivara. As respostas fornecidas pelos alunos nesta questão reforçam o que foi dito anteriormente nas questões 01 e 02, tendo em vista que uma parcela considerável das espécies aqui citadas não se enquadra nas definições de animais silvestres (BRASIL, 1998).

Ao serem questionados a respeito da prática de caça de animais silvestres, $2 \%$ dos alunos afirmaram que costumam caçar com frequência, 10\% afirmaram caçar raramente, enquanto $88 \%$ alegaram não possuir o hábito de caçar animais silvestres (Figura 1).

FIGURA 1. Percentual de alunos que costuma caçar animais silvestres.

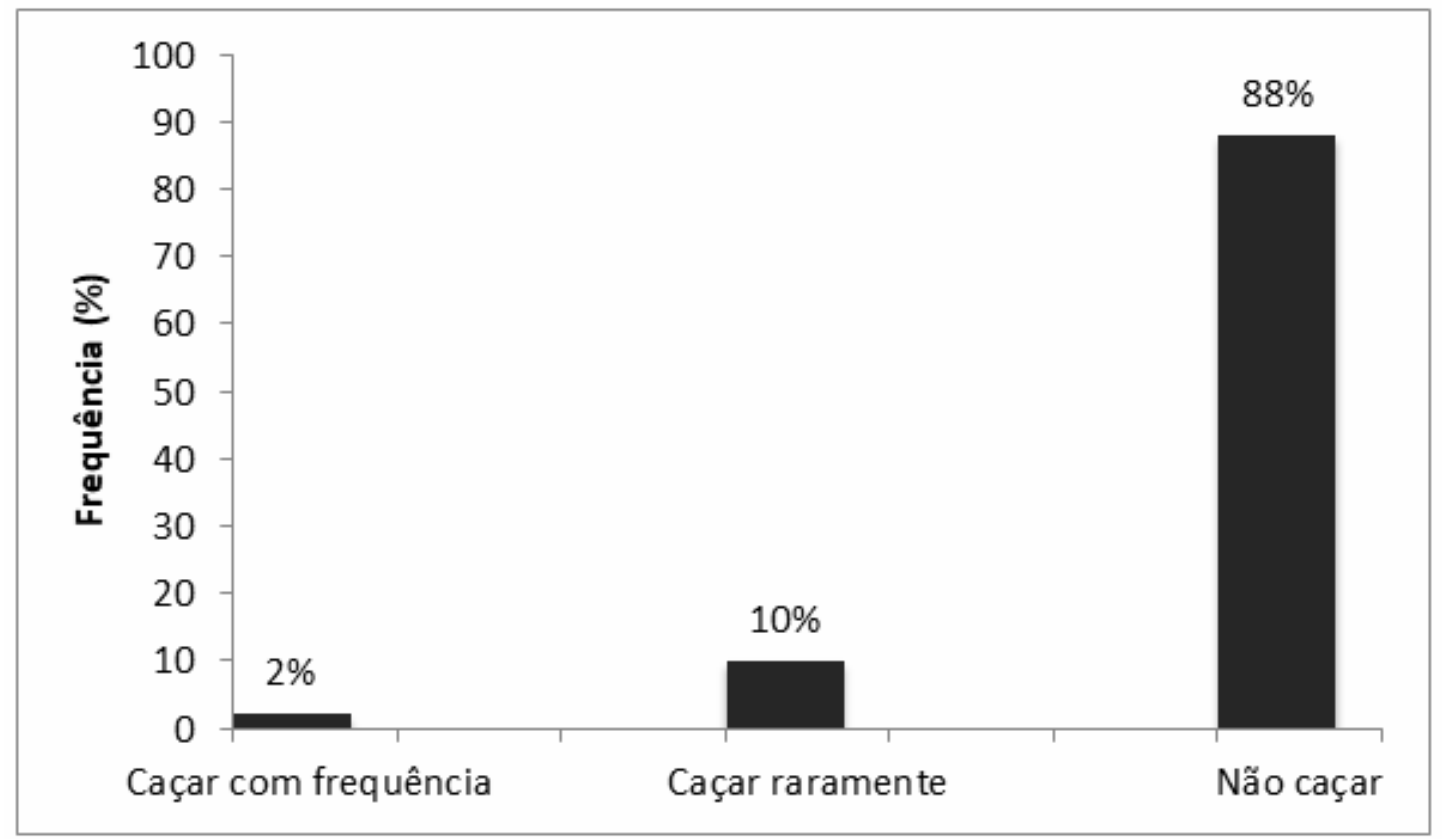

Fonte: Dados da pesquisa, (2019).

Pode-se notar que a grande maioria dos alunos entrevistados afirmou não possuir o hábito de caçar animais silvestres, estes alunos justificaram que os animais possuem o direito à vida e à liberdade; pelo fato da caça ser contra a lei e para evitar a extinção das espécies. Ressaltaram ainda a importância ecológica destes animais no ambiente onde estão inseridos. Em contrapartida, 12\% dos entrevistados, do sexo masculino, afirmaram praticar o hábito de caçar. De acordo com estes alunos, caçar trata-se de uma atividade de lazer ou ainda justificada por se tratar de um costume passado por outras gerações. 
Este discurso corrobora com os descritos por Sousa et al., (2020), no qual, a caça é uma tradição passada de geração em geração, onde os caçadores apresentam entre si relações de parentesco e amizade, e que este hábito legitima o vínculo entre os membros de uma comunidade. Geralmente, a prática de caçar animais silvestres iniciase na infância, influenciada pelos pais, sobretudo, envolvendo a avifauna regional. Ainda segundo Sousa et al., (2020), a relação dos pais ou pessoas mais velhas com o meio ambiente são reproduzidas pelas crianças, fazendo com que a caça, a pesca, a colheita de frutos e demais relações homem/meio ambiente sejam imitadas e iniciadas ainda na infância.

No item seguinte, ao serem questionados quanto a possuir animais domésticos, as espécies mais citadas com maior prevalência foram cães e gatos, seguidos por galinhas e pássaros. Os cães foram citados em 38\% das respostas, os gatos em 31\%, galinha $6 \%$, pássaro $3 \%$, cavalo $2 \%$, vaca $2 \%$, e finalmente $18 \%$ dos alunos afirmaram não possuir nenhum animal de estimação, como pode ser observado na Figura 2.

FIGURA 2. Percentual de alunos que possuíam animais domésticos em casa.

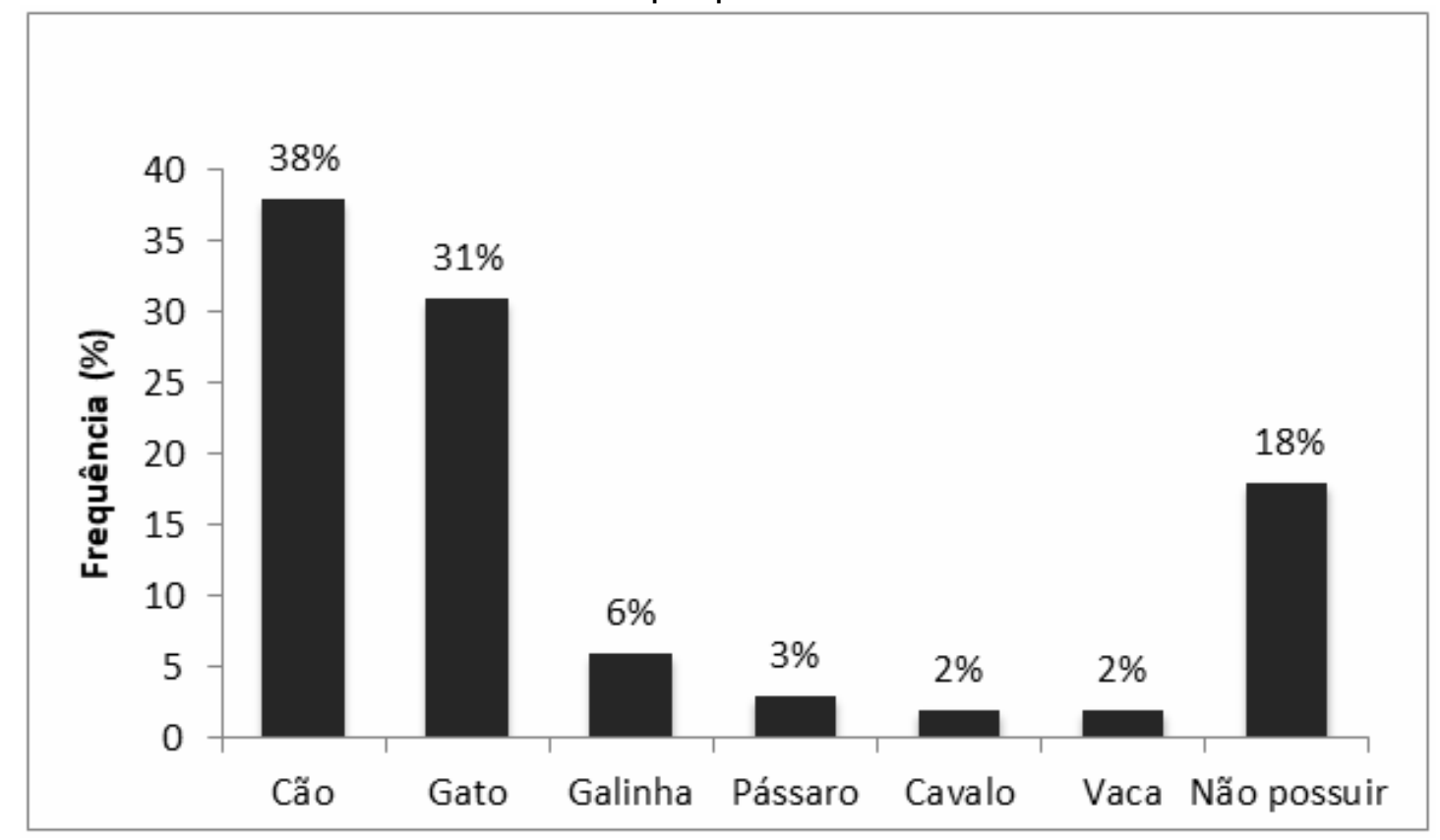

Fonte: Dados da pesquisa, (2019).

Este perfil de resposta era esperado, tendo em vista que grande parte destes alunos moram em áreas rurais, onde, além de desfrutarem da companhia de cães e gatos, existe também a presença de animais de produção como vacas e galinhas. e, também, por se tratar de um ambiente rural, o qual possui maior disponibilidade de aves silvestres, alguns alunos afirmaram cultivar o hábito de capturá-las e criá-las em gaiolas. Segundo Lopes e Freitas (2017), as aves são as espécies que mais sofrem com a apreensão e o tráfico de animais silvestres.

$\mathrm{Na}$ questão 6, ao serem indagados quanto a sua atitude ao receber ou encontrar um animal silvestre, $12 \%$ dos alunos responderam que criariam, $38 \%$ afirmaram que 
acionaria o IBAMA, 45\% afirmaram que soltariam o animal e, $5 \%$ venderiam ou consumiriam este animal (Figura 3).

FIGURA 3. Atitude tomada pelos estudantes ao receber/encontrar um animal silvestre.

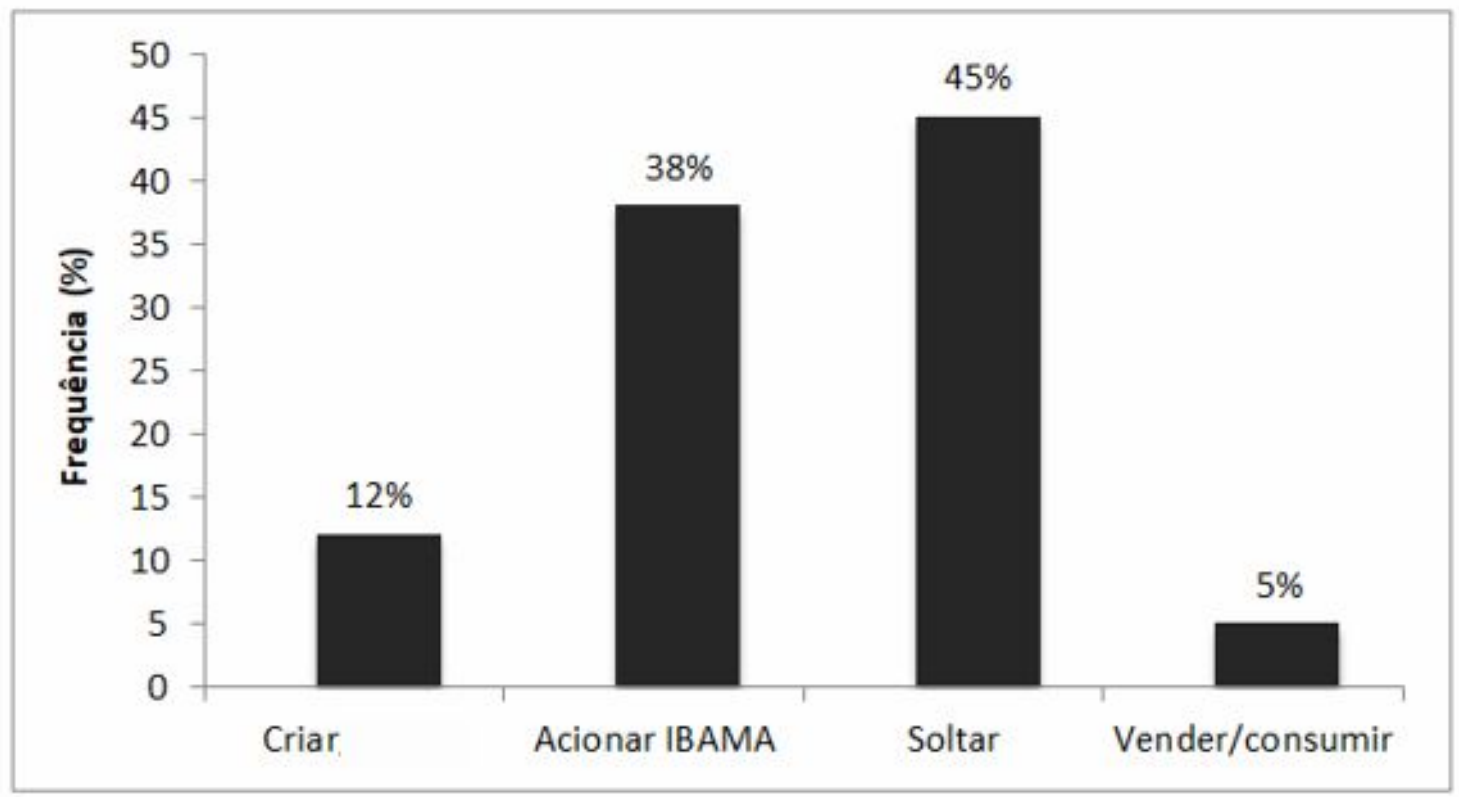

Fonte: Dados da pesquisa, (2019).

Ao serem questionados sobre o que é preciso fazer para possuir um animal diferente dos tradicionais em casa, $78 \%$ dos alunos entrevistados não souberam responder, enquanto $22 \%$ afirmaram a necessidade de um cadastro junto ao IBAMA, a fim de legalizar a criação deste animal. Evidenciou-se um alto número de alunos que desconhecem as medidas legais para possuir um animal silvestre. Este fato reforça a importância da educação ambiental como ferramenta educadora e mitigadora, promovendo a conscientização e desenvolvimento de novos padrões de conduta para com o meio ambiente (ALKIMIN et al., 2019; MUNIZ; PAZMINO, 2019; ROSÁRIO, 2019).

Quando questionados acerca do tráfico de animais silvestres e suas consequências, o perfil de respostas dos alunos sobre o tema foi de que o tráfico de animais é um crime com fins lucrativos, passivo de multa e prisão, além de ser responsável por acarretar consequências negativas para os animais, tais como sofrimento e maus tratos. Além disso, a captura e retirada destes animais da natureza desencadeiam um desequilíbrio ambiental e, consequentemente, a extinção de espécies. De acordo com os alunos, o tráfico é uma atitude de pessoas que não têm consciência ambiental.

Segundo Costa et al. (2018), em um estudo de meta-análise, constatou-se uma diversidade de espécies animais que sofrem com o contrabando no Brasil, sendo que $82 \%$ dos animais contrabandeados são aves, e que, muitas destas, são destinadas à alimentação humana. É importante ressaltar que animais silvestres são transmissores de diversos patógenos para os seres humanos, e, por isso, a criação ilegal destes ENCICLOPÉDIA BIOSFERA, Centro Científico Conhecer - Jandaia-GO, v.18 n.35; p. 121 2021 
animais em cativeiro, além de representar um problema para a conservação da espécie, representa também um problema para a saúde pública (MORAES; TIMM, 2019).

Segundo Costa et al. (2018), o tráfico internacional de animais silvestres no Brasil, movimenta cerca de 10 bilhões de dólares por ano. Assim como no mundo todo, o tráfico de animais representa um sério risco à biodiversidade brasileira, visto a representativa participação do Brasil nesse cenário. Ainda segundo os autores, nota-se uma rota típica no tráfico nacional, onde as regiões Norte, Nordeste e Centro-Oeste abastecem esse mercado ilegal, e as regiões Sudeste e Sul são os principais consumidores desses animais traficados, além de desempenharem o importante papel no tráfico internacional, funcionando como porta de saída de espécies nativas para outros países do mundo.

$\mathrm{Na}$ questão 09 foi indagado aos alunos como podem contribuir para a conservação da biodiversidade, 19\% afirmaram não saber e $79 \%$ dos alunos demonstraram notório conhecimento ao responderem que as medidas cabíveis são: não poluir os rios, não desmatar as florestas, não traficar animais, não realizar queimadas, não caçar animais silvestres, realizar campanhas preventivas que conscientizem as pessoas quanto à preservação da natureza, bem como o respeito à fauna e flora, ainda plantar árvores, descartar o lixo corretamente e respeitar as leis ambientais.

Ao serem questionados se o presente tema já foi trabalhado em alguma disciplina e qual a sua importância, os alunos responderam que o assunto foi trabalhado nas aulas de Biologia e que se trata de um tema de grande relevância tendo em vista promover a preservação do meio ambiente. De acordo com Muniz e Pazmino (2019), o processo educativo funciona como ferramenta promotora de transformações no atual quadro de degradação ambiental. Este processo pode ser construído a partir da aquisição de saberes e consciência, e, assim, subsidiando novos padrões de condutas relacionados à conservação da biodiversidade.

$\mathrm{Na}$ questão 11, os alunos foram indagados quanto a seu conhecimento sobre os queixadas, bem como as possíveis formas de conservação. Neste item, os alunos não souberam identificar a espécie em questão, contudo, no retorno à escola, que marca o momento da palestra, $100 \%$ dos alunos afirmaram ter ouvido falar em porcos do mato, embora não soubessem citar quais espécies compunham esta família. Inclusive, relataram práticas de caças a estes animais por parte de seus antepassados. No item 12, quando questionados sobre as contribuições da biotecnologia na conservação das espécies, todos os alunos entrevistados alegaram não saber do que se tratava. Por fim, no item 13, os estudantes foram questionados quanto à importância da relação entre pesquisa e ensino, neste quesito, todos os alunos afirmaram tal importância, ressaltando ser esta uma forma de esclarecimento sobre técnicas que são utilizadas em laboratório.

Em relação aos relatos coletados durante a mesa de diálogos, destacamos alguns pertinentes e que demonstram como a pesquisa e o ensino devem estar presentes no ensino básico, fomentando a iniciação científica, a produção autônoma do conhecimento e o pensamento crítico e reflexivo dos alunos, especialmente para a construção de uma nova ética ambiental:

[...] As respostas que dei no questionário, se pudesse, eu mudaria, pois, depois da palestra e da mesa de diálogos, vi que respondi muita baboseira. Aprendi 
tanto nestas atividades que me fizeram ver a questão ambiental de outra forma. Também fiquei curiosa quanto o professor apresentou o trabalho realizado para a conservação dos queixadas, que conhecia com porco do mato. Interessante saber como a biotecnologia tem ajudado na conservação dos animais [...]. (Aluna 28, 2019)

[...] Já tinha ouvido falar em porco do mato, mas não sabia que tinha várias espécies. Gostei de conhecer a pesquisa desenvolvida para conservação do Queixada. O nome científico eu esqueci. Isso! Tayassu pecari. Conhecendo como a pesquisa é feita, a questão da biotecnologia, dá até vontade de fazer Biologia para me tornar um pesquisador e descobrir outras coisas [...] (Aluno 12, 2019)

[...] Essa questão ambiental é muito importante. A gente ouve falar sempre, seja na escola ou na TV. Porém, acho que a grande diferença nesse trabalho foi a pesquisa que foi apresentada sobre a conservação dos queixadas, pois foi mostrado algo real para a gente ver que estão usando biotecnologia para garantir que essa espécie silvestre não corra o risco de ser extinta. Aprendi que a pesquisa é muito importante. Uma pena que no ensino médio não seja feita pesquisa, seria melhor para nossa formação. Depois da palestra, eu responderia diferente a pergunta do questionário sobre a pesquisa e o ensino estarem juntos [...]. (Aluna 37, 2019)

[...] Os problemas do meio ambiente só crescem a cada dia. E, muitas vezes, pensamos que nada é feito para mudar essa situação que pode colocar em risco a vida no planeta. Mas hoje vimos como a pesquisa para conservação dos animais, a biotecnologia e a educação ambiental podem sim mudar as coisas, só depende da mudança de mentalidade e de ação de cada um de nós [...] (Aluno 08, 2019)

Os relatos fornecidos pelos alunos evidenciam o desconhecimento sobre os queixadas, bem como sobre as possíveis formas de conservação desta espécie vulnerável a extinção. Pesquisas como estas fazem-se necessárias, sobretudo, tratando-se de alunos moradores da zona rural, os quais possuem contatos diários com os animais. Portanto, pôde-se notar a importância da inter-relação entre pesquisa e ensino, ao passo que os dados da presente pesquisa de doutorado extrapolaram os muros da Universidade, alcançando pessoas em fase de construção de identidade pessoal e profissional, sensibilizando-as para a conservação da fauna silvestre.

\section{CONCLUSÃO}

Verificou-se, antes das atividades de educação ambiental, que os estudantes detinham um conhecimento muito básico sobre as diferenças entre os animais domésticos, silvestres e selvagens, além de pouco conhecimento sobre legislação ambiental. Além disso, não conheciam os queixadas, tampouco as biotécnicas para conservação desta e de outras espécies. No entanto, estes mesmos alunos apresentaram um importante grau de preocupação com o bem-estar animal, proteção do meio ambiente e o cumprimento das leis ambientais. Estes preceitos são fundamentais para a aquisição de novos conhecimentos ambientais e uma postura ética frente aos desafios ambientais emergentes. Ademais, destacaram a importância da pesquisa no ensino médio, como forma de ampliar e produzir de maneira autônoma o conhecimento. Portanto, a educação ambiental no meio escolar, aliando pesquisa e ensino torna-se uma ferramenta eficaz para informar e conscientizar sobre questões atuais relacionadas à conservação do meio ambiente, sendo um instrumento essencial na mitigação dos problemas ambientais. 


\section{REFERÊNCIAS}

ALKIMIN, G. D.; MATOS, J. P.; QUEIROZ, T. V.; DORNFELD, C. B. A Educação Ambiental Escolar sob a perspectiva dos Professores do Ensino Médio (Ilha Solteira, SP). Revista Brasileira do Ensino Médio, v. 2, n. 1, p. 68-83, 2019. Disponível em:<https://phprbraem.com.br/ojs/index.php/RBRAEM/article/view/18>.

ALMEIDA, S. S.; DIAS, W. S.; MARQUES, J. S. Gestão ambiental: desenvolvimento e práticas sustentáveis. Revista Científica da Ajes, v. 7, n. 14, p. 11-19, 2018. Disponível em:<https://www.revista.ajes.edu.br/index.php/rca/article/view/144>.

BRASIL. Ministério de Educação. Secretaria de Educação Média e Tecnológica. Parâmetros Curriculares Nacionais - Ensino Médio. Brasília: MEC, 109p., 2000. Disponível em:<http://portal.mec.gov.br/seb/arquivos/pdf/blegais.pdf>.

BRASIL. Ministério do Meio Ambiente. Instituto Brasileiro de Meio Ambiente e dos Recursos Naturais Renováveis. Brasília: IBAMA. Portaria/IBAMA no 93, de 07 de Julho de $1998 . \quad$ Disponível em:<https://www.ibama.gov.br/component/legislacao/?view=legislacao\&force=1\&legisla cao $=102740>$.

CARVALHO, N. L.; RIBAS, M. A.; CARVALHO, T. G. M. L.; BARCELLOS, A. L. Percepção ambiental de alunos do ensino fundamental no município de Tupanciretã/RS. Revista Monografias Ambientais, v. 19, n. 7, p. 1-20, 2020. Disponível em:<https://periodicos.ufsm.br/remoa/article/view/40940>.

COSTA, F. J. V.; RIBEIRO, R. E.; SOUZA, C. A.; NAVARRO, R. D. Espécies de Aves Traficadas no Brasil: Uma Meta-Análise com Ênfase nas Espécies Ameaçadas. Journal of Social, Technological and Environmental Science, v.7, n.2, p. 324-346, 2018. Disponível em:<https://www.researchgate.net/publication/327356585_Especies_de_Aves_Traficad as_no_Brasil>. DOI: 10.21664/2238-8869.2018v7i2.p324-346

DIAS, M. A. S.; LIMA, N. B.; ANDRADE, C. A. F. Análise do conhecimento etnoherpetológico dos estudantes no município de Salinas, Minas Gerais, Brasil. ACTA

Biomedica Brasiliensia, v. 9, n. 1, 2018. Acesso em:<https://www.actabiomedica.com.br/index.php/acta/article/view/259>.

CRESWELL, J. W. Projeto de pesquisa: métodos qualitativo, quantitativo e misto. 2 ed. Porto Alegre: Artmed, 2007.

IUCN. International Union for Conservation of Nature. Guidelines for Applying Protected Area Management Categories, 143p., 2013. Disponível em: https://www.iucn.org/content/guidelines-applying-protected-area-managementcategories-including-iucn-wcpa-best-practice-guidance-recognising-protected-areasand-assigning-management-categories-and-governance-types 
KEUROGHILIAN, A.; DESBIEZ, A.; REYNA-HURTADO, R.; ALTRICHTER, M.; BECK, H.; TABER, A.; FRAGOSO, J. M. V. Tayassu pecari. IUCN Red List of Threatened Species. The IUCN Red List of Threatened Species, 2013. Disponível em: <https://dx.doi.org/10.2305/IUCN.UK.2013-1.RLTS.T41778A44051115.en>.

LEFEVRE, F.; LEFEVRE, A. M. C.; TEIXEIRA J.J.V. O Discurso do Sujeito Coletivo. Uma nova abordagem metodológica em pesquisa qualitativa. Caxias do Sul: Educs, 2000.

LEFF, E. Saber Ambiental: sustentabilidade, racionalidade, complexidade, poder. Petrópolis: Vozes, 2001.

LOPES, A.C.P.A.; FREITAS, M.A. Anomalias cromáticas em aves provenientes do tráfico de animais silvestres em Alagoas, Brasil. Atualidades Ornitológicas, v.198, p.42-46, 2017. Disponível em:<http://www.ao.com.br/download/A0198_42.pdf >.

MORAES, T. P.; TIMM, C. D. Importância dos animais silvestres como potenciais carreadores de patógenos alimentares. Medicina Veterinária (UFRPE), v.13, n.2, p.143-151, 2019.2 Disponível em:<http://www.journals.ufrpe.br/index.php/medicinaveterinaria/article/view/3036>. DOI: 10.26605/medvet-v13n2-3036

MOSSI, F. A responsabilidade civil-ambiental sob o viés do Direito Econômico e o uso consciente dos recursos naturais. In: BÜRING, M. A. (Org.) Responsabilidade civilambiental 2. Caxias do Sul: Educs, p. 52-63, 2019.

MUNIZ, J. P. S.; PAZMINO, A. V. O design na educação ambiental: requisitos para kit interdisciplinar sobre a perda da biodiversidade no Brasil. Mix Sustentável, v. 5, n. 22, p. 55-70, 2019.2 Disponível em:<https://ojs.sites.ufsc.br/index.php/mixsustentavel/article/view/3538>. DOI: 10.29183/2447-3073.MIX2019.v5.n2.55-70

PELIZZOLI, M. L. Correntes da Ética Ambiental. Petrópolis: Editora Vozes, 2002.

ROSÁRIO, C. S. Educação ambiental e atividades lúdicas para a identificação da importância das distintas formas de vida (fauna e flora). Revbea, v. 14, n. 3, p. 155-168, 2019. Disponível em:<https://periodicos.unifesp.br/index.php/revbea/article/view/2665>. DOI: 10.34024/revbea.2019.v14.2665

SAMPAIO, S. M. V. Pedagogias culturais e educação ambiental: mídia e cotidiano na sala de aula. In: SCHWANTS, L.; RIBEIRO, P. R. G. Ecos terrestres do sul: articulando os ecossistemas ao ensino de ciências. Rio Grande: Editora da FURG, p. 29-46, 2017.

SOUSA, J. V. O.; FIGUEIRÊDO, L. S.; VIEIRA, F. J.; MACEDO, E. M.; ARAGÃO, J. A. A caça de animais na Comunidade Quilombola Custaneira, em Paquetá do Piauí: entre 
mitos e crenças. Marupiara, v. 5, n. 6, p. 17-38, 2020. Disponível em:<http://periodicos.uea.edu.br/index.php/marupiara/article/view/1908>.

VIEIRA, R. L. A.; BENTO, H. J.; SOUZA, H. R.; COSTA, C. M.; ANDREA, M. V. Avifauna do Campus da Universidade Federal do Recôncavo da Bahia, Cruz Das Almas - BA. Enciclopédia Biosfera, v. 16 n.29; p. 1901-1910, 2019. Disponível em:< http://www.conhecer.org.br/enciclop/2019a/bio/avifauna.pdf>.

10.18677/EnciBio_2019A147. 